\title{
Disparate role of rhizobial ACC deaminase in root-nodule symbioses "
}

\section{Journal Article}

\section{Author(s):}

Murset, Valérie; Hennecke, Hauke; Pessi, Gabriella

Publication date:

2012-05

Permanent link:

https://doi.org/10.3929/ethz-b-000054562

Rights / license:

In Copyright - Non-Commercial Use Permitted

Originally published in:

Symbiosis 57(1), https://doi.org/10.1007/s13199-012-0177-z 


\title{
Disparate role of rhizobial ACC deaminase in root-nodule symbioses
}

\author{
Valérie Murset • Hauke Hennecke • Gabriella Pessi
}

Received: 29 February 2012 / Accepted: 7 July 2012 /Published online: 21 July 2012

(C) Springer Science+Business Media B.V. 2012

\begin{abstract}
The enzyme 1-aminocyclopropane-1-carboxylate (ACC) deaminase converts ACC, a precursor of the plant hormone ethylene, into ammonia and $\alpha$-ketobutyrate. ACC deaminase is widespread among the rhizobia in which it might play a crucial role in protecting rhizobia against inhibitory effects of ethylene synthesized by the host plant in response to the nodulation process. The beneficial action of this enzyme was demonstrated in several rhizobia such as Mesorhizobium loti and Rhizobium leguminosarum where knock-out mutants of the ACC deaminase gene showed nodulation defects. The genome of the slow-growing rhizobial species Bradyrhizobium japonicum also carries an annotated gene for a putative ACC deaminase (blr0241). Here, we tested the possible importance of this enzyme in B. japonicum by constructing an insertion mutant of blr0241 and studying its phenotype. First, the activity of ACC deaminase itself was measured. Unlike the $B$. japonicum wild type, the blr0241 mutant did not show any enzymatic activity. By contrast, the mutant was not impaired in its ability to nodulate soybean, cowpea, siratro, and mungbean. Likewise, symbiotic nitrogen fixation activity remained unaffected. Furthermore, a co-inoculation assay
\end{abstract}

Electronic supplementary material The online version of this article (doi:10.1007/s13199-012-0177-z) contains supplementary material, which is available to authorized users.

V. Murset $(\bowtie) \cdot H$. Hennecke

Institute of Microbiology, ETH Zürich,

Wolfgang-Pauli-Strasse 10,

8093 Zürich, Switzerland

e-mail: valerie.murset@micro.biol.ethz.ch

H. Hennecke

e-mail: hennecke@micro.biol.ethz.ch

G. Pessi

Institute of Plant Biology, University of Zürich,

Winterthurerstrasse 190,

8057 Zürich, Switzerland

e-mail: gabriella.pessi@botinst.uzh.ch with the B. japonicum wild type and the blr0241 mutant for soybean and siratro nodulation revealed that the mutant was not affected in its competitiveness for nodulation and nodule occupation. The results show that the role previously ascribed to ACC deaminase in the rhizobia cannot be generalized, and species-specific differences may exist.

Keywords 1-aminocyclopropane-1-carboxylic acid deaminase $\cdot$ Bradyrhizobium japonicum $\cdot$ Ethylene . Rhizobia $\cdot$ Root-nodule symbiosis

\section{Introduction}

Rhizobia are soil bacteria which can establish a symbiosis with legume host plants, therein acting as nitrogen-fixing endosymbionts. Symbiotic nitrogen fixation takes place in specific plant organs, the root nodules. To adapt to the symbiotic life-style, rhizobia have to cope with extremely low oxygen conditions as well as with host-plant responses to infection. One of the phytohormones that regulate nodulation is ethylene. This small and readily diffusible compound is well known to be involved in many aspects of the plant life cycle, including seed germination, root initiation, root hair development, fruit development and ripening (Abeles et al. 1992). Ethylene is also synthesized in response to abiotic (wounding, hypoxia, chilling) and biotic stresses (pathogen attack) which includes the interaction of plants with rhizobia (Spaink 1997; Abeles et al. 1992). In the latter case ethylene was reported to inhibit the nodulation of legumes (Lee and LaRue 1992; Nukui et al. 2000; Peters and Cristestes 1989). Studies on a Medicago truncatula ethylene insensitive mutant showed that during the initiation of symbiosis with Sinorhizobium meliloti, ethylene has an inhibitory effect on nodule formation by interfering with root hair deformation, infection thread initiation, calcium spiking, and 
rhizobial proliferation (Penmetsa and Cook 1997; Oldroyd et al. 2001; Tamimi and Timko 2003). In the Bradyrhizobium japonicum-legume symbioses, however, the effects of ethylene on nodulation are much less clear. It was previously shown that after inoculation with B. japonicum, the Glycine max (soybean) roots produce transiently more ethylene (Suganuma et al. 1995), but surprisingly, when an ethylene insensitive soybean mutant was inoculated with B. japonicum, no significant increase in nodule number was observed (Nukui et al. 2000; Schmidt et al. 1999). Moreover, the direct application of either $\mathrm{Ag}^{+}$, an inhibitor of ethylene perception, or 1aminocyclopropane-1-carboxylic acid (ACC, an intermediate of ethylene biosynthesis) on plant roots had no effect on soybean nodulation. Nevertheless, in the symbiosis between B. japonicum and another host plant Macroptilium atropurpureum (siratro), ethylene does appear to play an inhibitory role (Nukui et al. 2000).

Ethylene is synthesized in plants via three key reactions. First, the amino acid methionine is converted to $S$-adenosylL-methionine ( $S$-AdoMet) by the $S$-AdoMet synthetase. Second, the $S$-AdoMet is converted to ACC by the ACC synthase. Finally, ACC is converted to ethylene, carbon dioxide and hydrogen cyanide by the action of the ACC oxidase (Abeles et al. 1992; Lin et al. 2009).

Several soil-borne microorganisms use external mechanisms to influence ethylene levels in plants, either by synthesizing rhizobitoxine, a competitive inhibitor of the ACC synthase (Yasuta et al. 1999), or by expression of an ACC deaminase (AcdS) which degrades ACC into ammonia and $\alpha$-ketobutyrate (Ma et al. 2002). Regardless of whether ACC is constitutively present or newly synthesized in response to nodulation, the model of Glick et al. (1998) proposes that ACC is exuded from plant roots and taken up by the bacteria in which it would be metabolized as an energy and/or nitrogen source. This degradation would help lowering the amounts of ethylene provided by the plant. Hence, ACC deaminase would protect plants against the inhibitory effects of ethylene synthesized in response to stresses incurred by infecting bacteria.

The ACC deaminase is an oligomeric enzyme that carries pyridoxal 5-phosphate as an essential co-factor. The enzyme does not have a high affinity for its substrate ACC, with $K_{\mathrm{m}}$ values varying between 1.5 and $17.5 \mathrm{mM}$ (Honma and Shimomura 1978). This suggests that the enzyme can also degrade other substrates (Walsh et al. 1981). A broad range of organisms such as yeast and other fungi as well as few plants and several plant growth-promoting bacteria possess an ACC deaminase gene (Minami et al. 1998; Shah et al. 1998; Sterky et al. 1998; Jia et al. 2000; Riemenschneider et al. 2005).

The present paper serves two purposes. On the one hand, it explores for the first time the possible function of the $B$. japonicum ACC deaminase in the interaction with host legumes. On the other hand, as our data are in contrast with those obtained with other rhizobia, it summarizes the current knowledge with respect to the role of ACC deaminase in nodulation, which unveiled a certain degree of non-uniformity.

\section{Materials and methods}

\subsection{Bacterial strains, media and growth conditions}

Luria-Bertani (LB) medium was used for growth of Escherichia coli (Miller 1972). Cells of the B. japonicum wild-type strain $110 s p c 4$ and the blr0241 mutant strains were grown under aerobic condition with rigorous shaking (180 rpm) in PSY medium (Regensburger and Hennecke 1983) containing $0.1 \%$ L-arabinose and the antibiotic spectinomycin $\left(100 \mu \mathrm{g} \mathrm{ml}^{-1}\right)$. When appropriate, kanamycin $\left(100 \mu \mathrm{g} \mathrm{ml}^{-1}\right)$ was used for selections. Yeast-extract mannitol medium (Daniel 1972) supplemented with $10 \mathrm{mM} \mathrm{KNO}_{3}$ was used for anaerobic growth. Such cultures were grown with moderate shaking $(80 \mathrm{rpm})$ in 500-ml rubber-stoppered serum bottles containing $200 \mathrm{ml}$ medium and a gas atmosphere consisting of $100 \% \mathrm{~N}_{2}$.

\subsection{DNA methods and construction of blr0241 mutant strains}

Genomic DNA was isolated from B. japonicum wild-type strain $110 s p c 4$ as previously described (Hahn and Hennecke 1984). Recombinant DNA work was carried out according to standard procedures (Sambrook and Russell 2001). B. japonicum blr0241 mutant strains 6316 and 6317 were constructed by marker insertion mutagenesis. The $5^{\prime}$ and $3^{\prime}$ parts of the blr0241 gene were amplified by PCR using the following primer pairs (added restriction sites underlined): blr0241_up_f/Pst (AACTGCAGGGCGTCGTCG A A C A G G C ATC) and blr0241_up_r/KpnI (GGGGTACCTCCTCGCGCTTGGCATAGAT) for the $5^{\prime}$ region; blr0241_down_f/KpnI (GGGGTACCCTG CAACTCCGGCCTCGCCTA) and blr0241_down_r $/ X b a \mathrm{I}$ (GCTCTAGATGGCTTCGAGACGCGCGGTGAG) for the $3^{\prime}$ region. The 793-bp blr0241-5' region and the 690bp blr0241-3' region were cloned in the pGEM-T Easy vector (Promega Corp., Madison, WI, U.S.A.). After verification by sequencing, both products were eventually cloned tail-to-head into pSUP202pol6K (Zufferey et al. 1996). In two separate constructions, a 1,260 bp KpnI kanamycin resistance cassette (aphII) from pBSL86 (Alexeyev 1995) was inserted in either orientation into the unique $K p n I$ site between the blr0241-5' and $-3^{\prime}$ regions. The resulting plasmids pRJ6316 and pRJ6317 were mobilized into the $B$. japonicum wild-type strain 110spc4 (Hahn and Hennecke 1984) yielding mutants 6316 and 6317 with aphII in the opposite and same directions as blr0241, respectively. The correct genomic integrations were confirmed by PCR. The 
aphII insertion point is between genome coordinates 235,837 and 235,838 (http://genome.kazusa.or.jp/rhizobase/).

\subsection{Plant material, inoculation, and growth conditions}

Seeds of soybean (G. $\max ($ L.) Merr. cv. Williams), cowpea (Vigna unguiculata (L.) Walp. cv. Red Caloona), mungbean (Vigna radiata), and siratro (M. atropurpureum [DC.] Urb.) were surface-sterilized as recently described (Koch et al. 2010). Germination, inoculation, and growth of the plants were done as previously described (Hahn and Hennecke 1984; Göttfert et al. 1990). Nitrogenase activity in root nodules was determined at day 21 (soybean, cowpea, mungbean) or day 31 (siratro) post inoculation (dpi). For soybean, cowpea and siratro 10 plants inoculated with $B$. japonicum wild type 110spc 4 and 10 plants inoculated with the blr0241 mutant strain were tested. For mungbean 6 plants inoculated with $B$. japonicum wild type and 6 plants inoculated with the blr0241 mutant strain were tested. Nitrogenase activity was measured with the acetylene reduction assay (Hahn and Hennecke 1984; Göttfert et al. 1990). For the B. japonicum wild type $110 s p c 4$ versus mutant 6316 competition assay, two respective strain ratios (1:1 and 1:10) were tested for inoculation of soybean or siratro seedlings. Each ratio with 100 B. japonicum cells per seedling was applied to three soybean and four siratro plants. All of the nodules per plant were harvested at $21 \mathrm{dpi}$ for soybean and 31dpi for siratro. Total nodules from one plant were surface-sterilized for 5 min in $100 \%$ ethanol, washed 6 times with water, and then crushed. Bacteria were diluted and plated on selective agar plates. The competitiveness was assessed by comparing the proportional presence of each strain in the inoculum at time 0 to the proportional nodule occupancy of each strain after recovery from the nodules at 21 or $31 \mathrm{dpi}$.

\subsection{ACC deaminase activity assay}

The enzyme sources were crude extracts from either culture-grown cells or legume nodules. The B. japonicum wild-type strain $110 s p c 4$ and mutant strains 6316 and 6317 were grown in anoxic conditions for optimal induction of the blr0241 gene. Early stationary-phase cells were collected by centrifugation at $1,845 \mathrm{~g}$ for $10 \mathrm{~min}$ at $4{ }^{\circ} \mathrm{C}$. Nodules of cowpea, soybean, siratro and mungbean infected either with the $B$. japonicum wild type $110 s p c 4$ or with strain 6316 were disrupted as described previously (Pessi et al. 2007). The cell sediment corresponding to a $50-\mathrm{ml}$ anoxic culture was used for enzymatic tests as previously described (Penrose and Glick 2003). The substrates tested were from the following sources: ACC (Merck, Darmstadt, Germany); $\beta$-chloro-Dalanine hydrochloride and D-Serine (Sigma-Aldrich Co., St. Louis, MO, U.S.A.).

\section{Results and discussion}

3.1 A survey on the occurrence and function of the ACC deaminase gene $(a c d S)$ in the Rhizobiales

The $a c d S$ gene is widely spread among rhizobia (Online Resource 1). Presence of acdS in Rhizobium spp. was first reported by Ma et al. (2003a). In addition, an acdS-like gene can be detected with a database homology search (http:// www.ncbi.nlm.nih.gov) in the genomes of Agrobacterium, Bradyrhizobium, Mesorhizobium, Methylobacterium, some Sinorhizobium strains as well as in the $\beta$-rhizobial strains Burkholderia phymatum and Burkholderia tuberum (OnofreLemus et al. 2009). Most of the genomes tested have only one copy of $a c d S$. Few of the rhizobial acdS genes have been characterized by mutational analysis (Online Resource 1). A Mesorhizobium loti acdS knock-out mutant showed a decreased nodulation ability and was less competitive then the wild-type strain (Kaneko et al. 2000; Uchiumi et al. 2004) while a mutant constitutively expressing the $a c d S$ gene induced more nodules and was more competitive than the wild type (Conforte et al. 2010). Similarly, R. leguminosarum bv. viciae, mutants of either $a c d S$ or the associated regulatory gene ( $l p r L)$ led to a decreased nodule number (Ma et al. 2003b). However, these mutations did not affect nitrogen fixation, indicating that the ACC deaminase does not play a role in late steps of nodule development. A double knock-out mutant of acdS and $\operatorname{lrpL}$ of $A$. tumefaciens D3 significantly lost the ability to improve root elongation of canola seedlings as compared with the wild type (Hao et al. 2011). Furthermore, alfalfa nodulation by Sinorhizobium meliloti strain Rm1021, which lacks $a c d S$, was improved by the introduction of $a c d S$ from $R$. leguminosarum bv. viciae through plasmid transfer (Ma et al. 2004). Experiments along the same line were performed by Tittabutr et al. (2008) who introduced acdS from Sinorhizobium sp. strain BL3 in multiple copies into Rhizobium sp. strain TAL1145, a strain that exhibits only a low ACC deaminase activity. The resulting bacterial hybrid showed an increased ACC deaminase activity and led to an enhanced nodule number, nodule dry weight, and root dry weight in symbiosis with Leucaena. An acdS mutant of Rhizobium sp. strain TAL1145, however, did not cause a defective symbiotic phenotype on Leucaena. Another type of acdS-associated phenotype was observed after co-inoculation of mungbean seedlings with acdS-free Rhizobium phaseoli and the acdScontaining Pseudomonas syringae, which resulted in an increased host resistance to salt stress (Ahmad et al. 2011). Collectively, these reports argued for a beneficial role of ACC deaminase in the nodulation process. Yet, deviating findings - especially in the Bradyrhizobium-soybean symbiosis-, and the absence of $a c d S$ in some rhizobia made us wonder as to whether the reported positive effects can be generalized for every rhizobia-legume system. 


\subsection{Analysis of the B. japonicum acdS genomic region}

A putative ACC deaminase gene (blr0241; Fig. 1) has been annotated in the B. japonicum genome (Kaneko et al. 2002). This gene encodes a 337 -amino acid protein that has $87 \%$ and $74 \%$ positional amino acid sequence identity with the ACC deaminases of M. loti MAFF303099 and R. leguminosarum, respectively. A domain analysis of the Blr0241 protein shows the presence of a highly conserved region around a lysine at position 50 which is the essential amino acid that forms a covalent bond with the enzyme co-factor, pyridoxal-5'-phosphate (Yao et al. 2000; Fujino et al. 2004). Furthermore, it was previously shown that the tyrosine residues Y268 and Y294 are conserved in the known ACC deaminases (Karthikeyan et al. 2004). An alignment of the Blr0241 amino-acid sequence with the ACC deaminase sequences of Pseudomonas sp. and Hansenula saturnus (of which enzyme crystal structures are known) showed that these two residues are also conserved in B. japonicum ACC deaminase.

The gene located upstream of blr0241-i.e., bl10240 (Fig. 1) - is transcribed in the opposite direction and is predicted to code for a regulatory protein (AcdR) of the Lrp/AsnC family. Prigent-Combaret et al. (2008) noticed that $a c d R$ homologs are frequently associated with $a c d S$ in bacteria. These two genes co-occur also in some species of Pseudomonas, Burkholderia, and Ralstonia. The R. leguminosarum homolog of bll0240 was found to be required for expression of acdS (Ma et al. 2003b). AcdR of P. putida UW4 can bind to the $a c d S$ regulatory region, and a potential second regulatory protein, called AcdB was identified in this bacterium (Cheng et al. 2008). By analogy, although an AcdB homolog is absent in B. japonicum, the B110240 protein may act as a transcriptional regulator of the $a c d S$ gene in $B$. japonicum. Previous global transcript expression studies, using a custom-made Affymetrix GeneChip (Hauser et al. 2007), showed that bl10240 and blr0241 do not share the same expression profile. In contrast to bll0240, the acdSlike blr0241gene is highly expressed and up-regulated (20fold change) in soybean symbiosis as compared with the expression in culture-grown, aerobic cells (Online Resource 2; Pessi et al. 2007). We also performed a tiling analysis of blr0241 expression. Interestingly, expression strength depended on the oxygen-level. The acdS gene was upregulated during free-living micro-oxic (4.8-fold change) and anoxic growth (12-fold change) as well as in symbiosis (Online Resource 2, and Fig. 1). Induction under oxygen limitation clearly depended on the transcription factors RpoN $\left(\sigma^{54}\right)$ and NifA (data not shown, but cf. Hauser et al. 2007 and Pessi et al. 2007). However, in contrast to $M$.
Fig. 1 Transcription analysis and genomic environment of blr0241. a Hybridization signal intensities derived from individual oligonucleotide probe pairs of the blr0241 region, using $B$. japonicum mRNA from aerobic culture ( $\square$ ) and from soybean root-nodules (०). For better visualization, individual data points were connected by solid lines. The open reading frame of blr0241 is indicated by a line above the genome coordinates. b Map of the blr0241 genomic region and the insertion mutations. The black arrow indicates the blr0241 reading frame. The orientation of the inserted resistance cassette (aphII) is shown together with the corresponding B. japonicum strain numbers

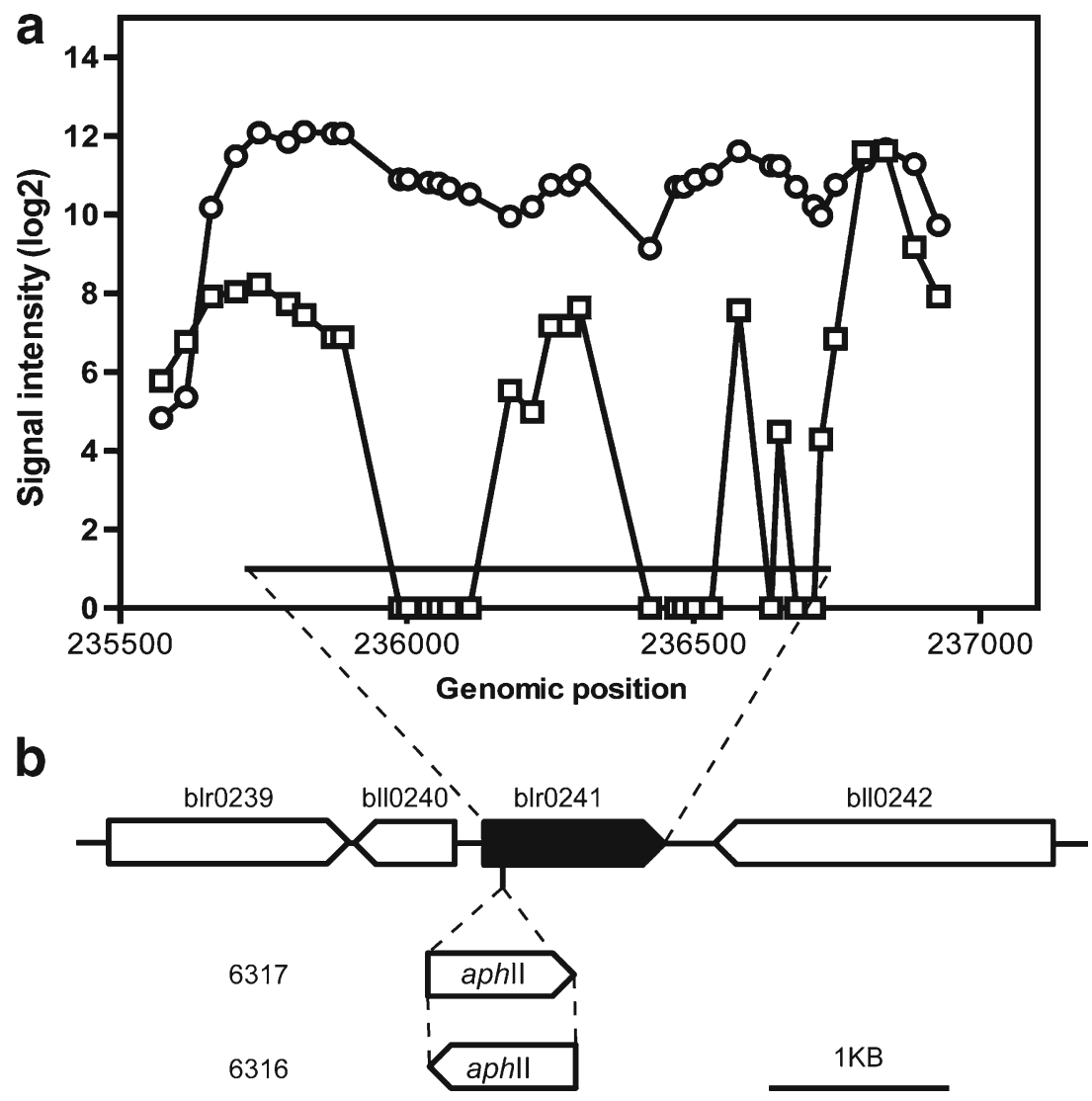


loti acdS (Nukui et al. 2006) the promoter region of blr0241 shows no predicted NifA or RpoN consensus binding sites suggesting that this gene might not be a direct target of these regulatory proteins. A proteomics study of B. japonicum revealed that ACC deaminase is abundant in root-nodule bacteroids of soybean, siratro, and cowpea $(853,477,527$ spectral counts, respectively) (Online Resource 2; Delmotte et al. 2010; Koch et al. 2010). Intuitively, the strong upregulation of blr0241 in B. japonicum bacteroids would be consistent with an important function of the ACC deaminase in soybean root-nodule symbiosis. To test this inference, blr0241 was mutated and the effect of the mutation was phenotypically analyzed.

\subsection{Construction and phenotypical analysis of a $B$.} japonicum ACC deaminase mutant

Knock-out mutants of blr0241 were constructed (strains 6316 and 6317) in which the $a c d S$-like gene was disrupted at nucleotide position 116 after the translational start codon by inserting a kanamycin resistance gene (aphII) (Fig. 1). The correct genomic structures of the mutants were confirmed by PCR (data not shown). The growth rates of the mutants in oxic and micro-oxic conditions were not impaired (data not shown). However, a moderate growth delay was observed in anoxic, denitrifying conditions (Fig. 2), suggesting that the blr0241 gene product might play a supportive role while $B$. japonicum is growing anoxically. Furthermore, the colony forming units (CFU) of the mutant growing in complex PSY medium in aerobic condition decreased 2.3-fold as compared with the wild-type, i.e., at an optical density $\left(\mathrm{OD}_{600}\right)$ of 1 the wild-type CFU was $10^{9}$ bacteria per $\mathrm{ml}$, whereas that of strain 6316 was $4.4 \times 10^{8}$.

In order to unveil a possible role of blr0241 during symbiosis, seedlings of soybean, siratro, cowpea and mungbean plants were inoculated with the $B$. japonicum wild type

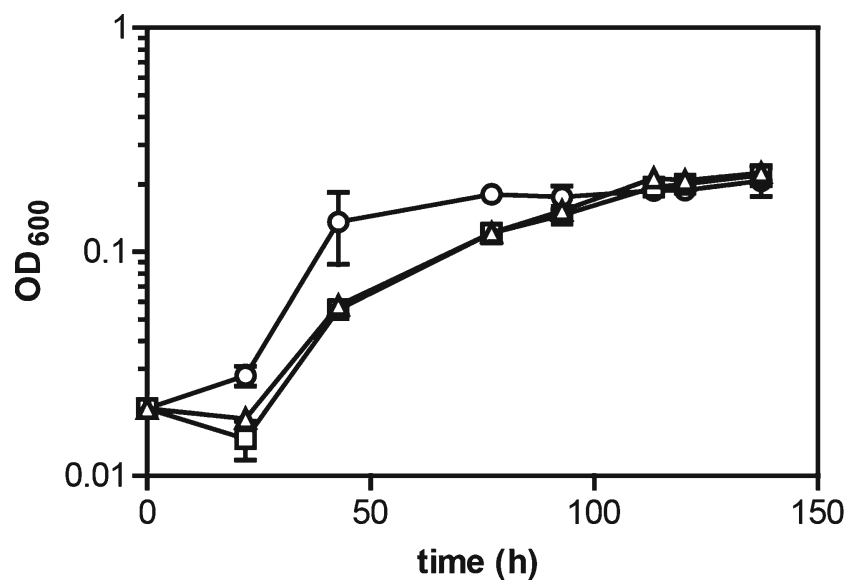

Fig. 2 Growth of the B. japonicum wild type (०) and mutant strains $6316(\square)$ and $6317(\Delta)$ in anoxic condition with nitrate as the terminal electron acceptor and strain 6316. After 21 days (soybean, cowpea, and mungbean) and 31 days (siratro), whole-nodule symbiotic nitrogen fixation activity was measured with the standard acetylene reduction test. Plants inoculated with the mutant did not exhibit a defect in symbiotic nitrogen fixation as compared with plants inoculated with the wild type. Moreover morphology, number and dry weight of nodules induced by the mutant were wild-type like. To test whether the blr0241 mutant has perhaps a more subtle nodulation deficiency that escaped detection, a competition assay on soybean and siratro was performed between the wild type and 6316 strain. Figure 3 clearly shows that the mutant was as competitive as the wild type in colonizing soybean and siratro root nodules. Hence, the $B$. japonicum acdS-like gene does not appear to play a crucial role in the initiation and formation of a root nodule symbiosis. These results were unexpected in view of the fact that deletion of $a c d S$ in other rhizobia led to noticeable defects in terms of nodule number, shoot dry weight, or competition efficiency (Ma et al. 2003b; Uchiumi et al. 2004). This raised concerns about whether or not the B. japonicum acdS-like gene indeed encodes a functional ACC deaminase.

\subsection{B. japonicum ACC deaminase activity assay}

To prove that the $a c d S$ gene encodes a functional enzyme in $B$. japonicum, the ACC deaminase activity was assayed. Measurements were done with the $B$. japonicum wild type and the insertion mutant 6316 , both grown under anoxic free-living condition and in symbiosis with different host plants. In anoxic, free-living culture, the wild type had an activity of

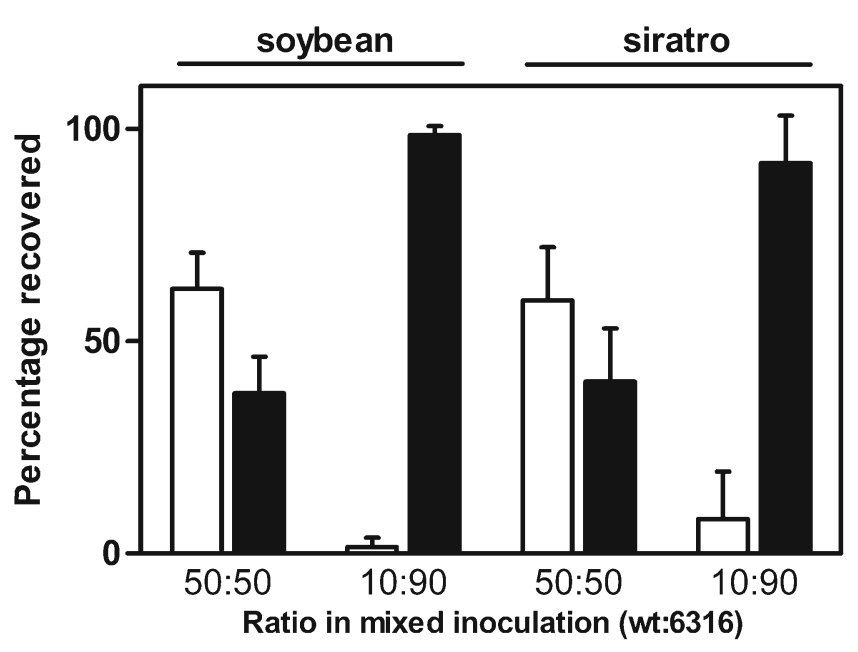

Fig. 3 Competition assay for soybean and siratro inoculation with the $B$. japonicum wild type (wt) and mutant 6316. The mixed inoculum contained wild type and strain 6316 in two different ratios as indicated. The percentage of in-nodule occupancy was determined by re-isolation of viable bacteria (from all nodules from each plant) and identification of their antibiotic resistance profile. The columns reflect the recovery of the wild type (white bars) and the mutant (black bars) as \% of total isolates 
$1.49 \mu$ moles $\alpha$-ketobutyrate $/ \mathrm{mg} / \mathrm{h}$ whereas the insertion mutant showed no activity beyond background levels (Table 1). The ACC deaminase activity in root nodules varied depending on the host plant (Table 1). While the wild type-infected nodules consistently displayed a higher activity than mutantinfected nodules, we noticed a substantial background activity in the latter. One explanation could be that this activity stems from a host plant ACC deaminase, although we did not find an acdS-like gene in the sequenced soybean genome by homology search (Schmutz et al. 2010). Alternatively, this unexpected activity might be explained by the presence of plant compounds other than $\alpha$-ketobutyrate, having aldehyde or keto groups that would be detected by the 2,4-dinitrophenylhydrazine reagent in the assay.

Intriguingly, it was shown previously with the ACC deaminase from Pseudomonas sp. that the enzyme can use substrates other than ACC, such as D-serine and D- $\beta$-chloroalanine (Walsh et al. 1981). Therefore, we also tested the B. japonicum enzyme present in crude cellular extracts for activity with these two substrates. A low but significant activity was detected with D-serine as the substrate which corresponded to about $10 \%$ of the activity measured with ACC as the substrate. D- $\beta$ chloroalanine was not used as a substrate. The low activity measured with D-serine corroborates the notion that the Blr0241 protein might be a slightly promiscuous enzyme, just like the Pseudomonas sp. ACC deaminase (Walsh et al. 1981). Thus, the possibility cannot be excluded that the blr0241encoded enzyme uses not only ACC but also other compounds that might be present in the host plant or in the bacterium.

\subsection{Concluding remarks}

The use of ACC by plant-associated, Gram-negative bacteria would require (i) that plants secrete $\mathrm{ACC}$ despite the necessity to convert it to ethylene in planta, and (ii) that bacteria take up ACC through the outer and the cytoplasmic membranes so that it can be used intracellularly as a substrate for degradation. None of these transport processes has ever been demonstrated in any plant-microbe system.

Table 1 Determination of ACC deaminase activity ( $\mu$ mol 2ketobutyrate formed $\mathrm{h}^{-1} \mathrm{mg}_{\text {protein }}^{-1}$ ) in $B$. japonicum cells grown free-living and in symbiosis

\begin{tabular}{lll}
\hline Growth condition & Wild type & Strain 6316 \\
\hline $\begin{array}{l}\text { Free-living } \\
\text { In anoxic culture }\end{array}$ & $1.49 \pm 0.01$ & $0.053 \pm 0.0$ \\
Symbiotic & & \\
In soybean nodules & $0.47 \pm 0.0$ & $0.17 \pm 0.0$ \\
In mungbean nodules & $1.52 \pm 0.0$ & $0.45 \pm 0.11$ \\
In siratro nodules & $0.78 \pm 0.04$ & $0.48 \pm 0.08$ \\
In cowpea nodules & $1.02 \pm 0.05$ & $0.59 \pm 0.016$ \\
\hline
\end{tabular}

Therefore, it remains a mystery how ACC reaches ACC deaminase on its way from the site of synthesis to the site of degradation. Nevertheless, there are reports that show for rhizobia a beneficial effect of possessing ACC deaminase. In the present paper, however, the data obtained with $B$. japonicum-legume symbioses do not support such a claim. The most clear-cut result was that a $B$. japonicum acdS (blr0241) knock-out mutant displayed an unaltered, wildtype behavior in the processes of nodulation and symbiotic nitrogen fixation with four different host plants. The lack of any effect, which was additionally confirmed in a more sensitive nodulation competition assay, might have been expected at least for the B. japonicum-soybean symbiosis, because previous investigations had already shown that soybean nodulation was independent of ethylene signaling (Schmidt et al. 1999). Yet, the nodulation process on siratro, another host of B. japonicum, did show an involvement of the ethylene signaling pathway (Nukui et al. 2000), which we cannot support due to the lack of an effect caused by the blr0241 mutation on siratro nodulation and the absence of a competition defect in comparison to the wild type. By and large, the beneficial effect of ACC deaminase seen in several rhizobia-legume symbioses cannot be extrapolated uncritically to all nodulating plants.

The question arises as to why the expression of the $B$. japonicum blr0241 gene is strongly up-regulated under low oxygen conditions such as it prevails in root nodules (Hauser et al. 2007; Pessi et al. 2007). One possibility is that rhizobial ACC deaminase plays an important role in micro-oxic or anoxic metabolism rather than attenuating plant-internal ethylene synthesis. Moreover, one might even go as far as to suggest that a hitherto unidentified metabolite other than ACC is the true in-vivo substrate for rhizobial ACC deaminase. What speaks in favor of this statement is the remarkable substrate promiscuity of the enzyme and the very poor affinity constant for ACC (Honma and Shimomura 1978; Walsh et al. 1981). In this context, it is interesting to note that the Arabidopsis thaliana ACC deaminase had originally been discovered as a D-cysteine desulfhydrase (Riemenschneider et al. 2005). In our own study, we confirmed that the Blr0241 protein uses D-serine as a substrate, although less efficiently than ACC. This might be interpreted to mean that the true substrate for ACC deaminase has yet to be discovered, and the corresponding substrate conversion might be unrelated to the nodulation process. In line with this inference, we made the disillusioning experience that strong expression of a gene in bacteroids is no guarantee for its importance in symbiosis.

Acknowledgments Financial support for this work was provided by the Swiss National Science Foundation and the ETH Zürich. We thank Dieter Haas for alerting us to the broad substrate specificity of ACC deaminase. 


\section{References}

Abeles FB, Morgan PW, Saltveit ME (1992) Ethylene in plant biology, 2nd edn. Academic, San Diego

Ahmad M, Zahir ZA, Asghar HN, Asghar M (2011) Inducing salt tolerance in mung bean through coinoculation with rhizobia and plant-growth-promoting rhizobacteria containing 1aminocyclopropane-1-carboxylate deaminase. Can J Microbiol 57:578-589

Alexeyev MF (1995) Three kanamycin resistance gene cassettes with different polylinkers. Biotechniques 18:52-56

Cheng Z, Duncker BP, McConkey BJ, Glick BR (2008) Transcriptional regulation of ACC deaminase gene expression in Pseudomonas putida UW4. Can J Microbiol 54:128-136

Conforte VP, Echeverria M, Sanchez C, Ugalde RA, Menendez AB, Lepek VC (2010) Engineered ACC deaminase-expressing freeliving cells of Mesorhizobium loti show increased nodulation efficiency and competitiveness on Lotus spp. J Gen Appl Microbiol 56:331-338

Daniel RM (1972) Anaerobic-nitrate, symbiotic and aerobic growth of Rhizobium japonicum. Effects on cytochrome P450, other hemoproteins, nitrate and nitrite reductases. Biochim Biophys Acta Bioenerg 275:347-354

Delmotte N, Ahrens CH, Knief C, Qeli E, Koch M, Fischer HM, Vorholt JA, Hennecke H, Pessi G (2010) An integrated proteomics and transcriptomics reference data set provides new insights into the Bradyrhizobium japonicum bacteroid metabolism in soybean root nodules. Proteomics 10:1391-1400

Fujino A, Ose T, Yao M, Tokiwano T, Honma M, Watanabe N, Tanaka I (2004) Structural and enzymatic properties of 1-aminocyclopropane1-carboxylate deaminase homologue from Pyrococcus horikoshii. J Mol Biol 341:999-1013

Glick BR, Penrose DM, Li JP (1998) A model for the lowering of plant ethylene concentrations by plant growth-promoting bacteria. J Theor Biol 190:63-68

Göttfert M, Hitz S, Hennecke H (1990) Identification of nodS and nod $U$, two inducible genes inserted between the Bradyrhizobium japonicum nodYABC and nodIJ genes. Mol Plant-Microbe Interact 3:308-316

Hahn M, Hennecke H (1984) Localized mutagenesis in Rhizobium japonicum. Mol Gen Genet 193:46-52

Hao Y, Charles TC, Glick BR (2011) ACC deaminase activity in avirulent Agrobacterium tumefaciens D3. Can J Microbiol 57:278-286

Hauser F, Pessi G, Friberg M, Weber C, Rusca N, Lindemann A, Fischer HM, Hennecke H (2007) Dissection of the Bradyrhizobium japonicum $\mathrm{NifA}+\sigma^{54}$ regulon, and identification of a ferredoxin gene $(f d x N)$ for symbiotic nitrogen fixation. Mol Genet Genomics 278:255-271

Honma M, Shimomura T (1978) Metabolism of 1-aminocyclopropane1-carboxylic acid. Agric Biol Chem 42:1825-1831

Jia YJ, Ito H, Matsui H, Honma M (2000) 1-aminocyclopropane-1carboxylate (ACC) deaminase induced by ACC synthesized and accumulated in Penicillium citrinum intracellular spaces. Biosci Biotechnol Biochem 64:299-305

Kaneko T, Nakamura Y, Sato S, Asamizu E, Kato T, Sasamoto S, Watanabe A, Idesawa K, Ishikawa A, Kawashima K, Kimura T, Kishida Y, Kiyokawa C, Kohara M, Matsumoto M, Matsuno A, Mochizuki Y, Nakayama S, Nakazaki N, Shimpo S, Sugimoto M, Takeuchi C, Yamada M, Tabata S (2000) Complete genome structure of the nitrogen-fixing symbiotic bacterium Mesorhizobium loti. DNA Res 7:331-338

Kaneko T, Nakamura Y, Sato S, Minamisawa K, Uchiumi T, Sasamoto S, Watanabe A, Idesawa K, Iriguchi M, Kawashima K, Kohara M, Matsumoto M, Shimpo S, Tsuruoka H, Wada T, Yamada M,
Tabata S (2002) Complete genomic sequence of nitrogen-fixing symbiotic bacterium Bradyrhizobium japonicum USDA110. DNA Res 9:189-197

Karthikeyan S, Zhou QX, Zhao ZB, Kao CL, Tao ZH, Robinson H, Liu HW, Zhang H (2004) Structural analysis of Pseudomonas 1aminocyclopropane-1-carboxylate deaminase complexes: Insight into the mechanism of a unique pyridoxal-5'-phosphate dependent cyclopropane ring-opening reaction. Biochemistry 43:1332813339

Koch M, Delmotte N, Rehrauer H, Vorholt JA, Pessi G, Hennecke H (2010) Rhizobial adaptation to hosts, a new facet in the legume root-nodule symbiosis. Mol-Plant Microbe Interact 23:784-790

Lee KH, LaRue TA (1992) Exogenous ethylene inhibits nodulation of Pisum sativum L. cv Sparkle. Plant Physiol 100:1759-1763

Lin ZF, Zhong SL, Grierson D (2009) Recent advances in ethylene research. J Exp Bot 60:3311-3336

Ma WB, Penrose DM, Glick BR (2002) Strategies used by rhizobia to lower plant ethylene levels and increase nodulation. Can J Microbiol 48:947-954

Ma WB, Sebestianova SB, Sebestian J, Burd GI, Guinel FC, Glick BR (2003a) Prevalence of 1-aminocyclopropane-1-carboxylate deaminase in Rhizobium spp. A van Leeuw J Microb 83:285-291

Ma WB, Guinel FC, Glick BR (2003b) Rhizobium leguminosarum bv. viciae 1-aminocyclopropane-1 carboxylate deaminase promotes nodulation of pea plants. Appl Environ Microbiol 69:4396-4402

Ma WB, Charles TC, Glick BR (2004) PV expression of an exogenous 1-aminocyclopropane 1-carboxylate deaminase gene in Sinorhizobium meliloti increases its ability to nodulate alfalfa. Appl Environ Microbiol 70:5891-5897

Miller JH (1972) Experiments in molecular genetics. Cold Spring Laboratories, Cold Spring Harbour

Minami R, Uchiyama K, Murakami T, Kawai J, Mikami K, Yamada T, Yokoi D, Ito H, Matsui H, Honma M (1998) Properties, sequence, and synthesis in Escherichia coli of 1-aminocyclopropane-1-carboxylate deaminase from Hansenula saturnus. J Biochem 123:1112-1118

Nukui N, Ezura H, Yuhashi KI, Yasuta T, Minamisawa K (2000) Effects of ethylene precursor and inhibitors for ethylene biosynthesis and perception on nodulation in Lotus japonicus and Macroptilium atropurpureum. Plant Cell Physiol 41:893-897

Nukui N, Minamisawa K, Ayabe SI, Aoki T (2006) Expression of the 1-aminocyclopropane-1-carboxylic acid deaminase gene requires symbiotic nitrogen-fixing regulator gene nifA2 in Mesorhizobium loti MAFF303099. Appl Environ Microbiol 72:4964-4969

Oldroyd GED, Engstrom EM, Long SR (2001) Ethylene inhibits the nod factor signal transduction pathway of Medicago truncatula. Plant Cell 13:1835-1849

Onofre-Lemus J, Hernández-Lucas I, Girard L, Caballero-Mellado J (2009) ACC (1-aminocyclopropane-1-carboxylate) deaminase activity, a widespread trait in Burkholderia species, and its growthpromoting effect on tomato plants. Appl Environ Microbiol 75:6581-6590

Penmetsa RV, Cook DR (1997) A legume ethylene-insensitive mutant hyperinfected by its rhizobial symbiont. Science 275:527-530

Penrose DM, Glick BR (2003) Methods for isolating and characterizing ACC deaminase-containing plant growth-promoting rhizobacteria. Plant Physiol 118:10-15

Pessi G, Ahrens CH, Rehrauer H, Lindemann A, Hauser F, Fischer HM, Hennecke H (2007) Genome-wide transcript analysis of Bradyrhizobium japonicum bacteroids in soybean root nodules. Mol Plant-Microbe Interact 20:1353-1363

Peters NK, Cristestes DK (1989) Nodule formation is stimulated by the ethylene inhibitor aminoethoxyvinylglycine. Plant Physiol 91:690-693

Prigent-Combaret C, Blaha D, Pothier JF, Vial L, Poirier MA, Wisniewski-Dyé F, Moënne-Loccoz Y (2008) Physical organization 
and phylogenetic analysis of AcdR as leucine-responsive regulator of the 1-aminocyclopropane-1-carboxylate deaminase gene $a c d S$ in phytobenefical Azospirillum lipoferum 4B and other Proteobacteria. FEMS Microbiol Ecol 65:202-219

Regensburger B, Hennecke H (1983) RNA polymerase from Rhizobium japonicum. Arch Microbiol 135:103-109

Riemenschneider A, Bonacina E, Schmidt A, Papenbrock J (2005) Isolation and characterization of a second D-cysteine desulfhydraselike protein from Arabidopsis. In: Saito K, De Kok LJ, Stulen I, Hawkesford MJ, Schnug E, Sirko A, Rennenberg H (eds) Sulfur transport and assimilation in plants in the post genomic era. Backhuys Publishers, Leiden, pp 103-106

Sambrook J, Russell DW (2001) Molecular cloning: a laboratory manual. Cold Spring Harbour Laboratory Press, New York

Schmidt JS, Harper JE, Hoffman TK, Bent AF (1999) Regulation of soybean nodulation independent of ethylene signaling. Plant Physiol 119:951-959

Schmutz J, Cannon SB, Schlueter J, Ma J, Mitros T, Nelson W, Hyten DL, Song Q, Thelen JJ, Cheng J, Xu D, Hellsten U, May GD, Yu Y, Sakurai T, Umezawa T, Bhattacharyya MK, Sandhu D, Valliyodan B, Lindquist E, Peto M, Grant D, Shu S, Goodstein D, Barry K, Futrell-Griggs M, Abernathy B, Du J, Tian Z, Zhu L, Gill N, Joshi T, Libault M, Sethuraman A, Zhang XC, Shinozaki K, Nguyen HT, Wing RA, Cregan P, Specht J, Grimwood J, Rokhsar D, Stacey G, Shoemaker RC, Jackson SA (2010) Genome sequence of the palaeopolyploid soybean. Nature 463:178-183

Shah S, Li JP, Moffatt BA, Glick BR (1998) Isolation and characterization of ACC deaminase genes from two different plant growthpromoting rhizobacteria. Can J Microbiol 44:833-843

Spaink HP (1997) Ethylene as a regulator of Rhizobium infection. Trends Plant Sci 2:203-204

Sterky F, Regan S, Karlsson J, Hertzberg M, Rohde A, Holmberg A, Amini B, Bhalerao R, Larsson M, Villarroel R, Van Montagu M, Sandberg G, Olsson O, Teeri TT, Boerjan W, Gustafsson P, Uhlen
M, Sundberg B, Lundeberg J (1998) Gene discovery in the woodforming tissues of poplar: analysis of 5,692 expressed sequence tags. Proc Natl Acad Sci USA 95:13330-13335

Suganuma N, Yamauchi H, Yamamoto K (1995) Enhanced production of ethylene by soybean roots after inoculation with Bradyrhizobium japonicum. Plant Sci 111:163-168

Tamimi SM, Timko MP (2003) Effects of ethylene and inhibitors of ethylene synthesis and action on nodulation in common bean (Phaseolus vulgaris L.). Plant Soil 257:125-131

Tittabutr P, Awaya JD, Li QX, Borthakur D (2008) The cloned 1aminocyclopropane-1-carboxylate (ACC) deaminase gene from Sinorhizobium sp. strain BL3 in Rhizobium sp. strain TAL1145 promotes nodulation and growth of Leucaena leucocephala. Syst Appl Microbiol 31:141-150

Uchiumi T, Ohwada T, Itakura M, Mitsui H, Nukui N, Dawadi P, Kaneko T, Tabata S, Yokoyama T, Tejima K, Saeki K, Omori H, Hayashi M, Maekawa T, Sriprang R, Murooka Y, Tajima S, Simomura K, Nomura M, Suzuki A, Shimoda Y, Sioya K, Abe M, Minamisawa K (2004) Expression islands clustered on the symbiosis island of the Mesorhizobium loti genome. J Bacteriol 186:2439-2448

Walsh C, Pascal RA, Johnston M, Raines R, Dikshit D, Krantz A, Honma M (1981) Mechanistic studies on the pyridoxal-phosphate enzyme 1-aminocyclopropane-1 carboxylate deaminase from Pseudomonas sp. Biochemistry 20:7509-7519

Yao M, Ose T, Sugimoto H, Horiuchi A, Nakagawa A, Wakatsuki S, Yokoi D, Murakami T, Honma M, Tanaka I (2000) Crystal structure of 1-aminocyclopropane-1-carboxylate deaminase from Hansenula saturnus. J Biol Chem 275:34557-34565

Yasuta T, Satoh S, Minamisawa K (1999) New assay for rhizobitoxine based on inhibition of 1-aminocyclopropane-1-carboxylate synthase. Appl Environ Microbiol 65:849-852

Zufferey R, Preisig O, Hennecke H, Thöny-Meyer L (1996) Assembly and function of the cytochrome $c b b_{3}$ oxidase subunits in Bradyrhizobium japonicum. J Biol Chem 271:9114-9119 